\title{
QUADERNI Quaderni
}

Communication, technologies, pouvoir

99-100 | Hiver 2019-2020

\section{Technologies et jeux de pouvoir}

\section{Fictions du pouvoir}

\section{Emmanuel Taïeb et Étienne Candel}

\section{OpenEdition}

Journals

Édition électronique

URL : https://journals.openedition.org/quaderni/1527

DOI : 10.4000/quaderni.1527

ISSN : 2105-2956

\section{Éditeur}

Les éditions de la Maison des sciences de l'Homme

\section{Édition imprimée}

Date de publication : 5 janvier 2020

Pagination : 5-6

\section{Référence électronique}

Emmanuel Taïeb et Étienne Candel, « Fictions du pouvoir », Quaderni [En ligne], 99-100 | Hiver 2019-2020, mis en ligne le 05 janvier 2020, consulté le 05 janvier 2023. URL : http://

journals.openedition.org/quaderni/1527 ; DOI : https://doi.org/10.4000/quaderni.1527 


\section{$D$ ossier}

\section{Avant-propos Fictions $d u$}

À la fois hommage à Lucien Sfez, fondateur des Quaderni en 1987, et centième parution, le numéro que nous vous proposons entend revisiter et actualiser ce qui a fait la spécificité de la revue depuis sa création. En particulier la pensée pouvoir critique - critique des idéologies qui nourrissent la pensée d'État -, qui n'est pas l'apanage d'une école ou d'une discipline particulières. Travailler sur les sommets de l'État, sur ses outils, sur la décision, et surtout sur les représentations sociopolitiques et communicationnelles qui peuplent

Emmanuel

Taïeb

Co-directeur de Quaderni Sciences Po Lyon Triangle

\section{Étienne Candel}

Co-directeur de Quaderni Université Lyon 3 Jean Moulin Elico les esprits des acteurs du pouvoir comme des publics revient à identifier la façon dont l'idéologie s'est métamorphosée dans la seconde moitié du $\mathrm{XX}^{\mathrm{e}}$ siècle. Non plus l'idéologie messianique, devenue religion séculière, du début du $\mathrm{XX}^{\mathrm{e}}$ siècle, mais bien celle qui s'est coulée dans le moule du droit administratif et du légal-rationnel wébérien.

Si Lucien Sfez s'est passionné pour Port-Royal, pour la théorie des deux corps du roi d'Ernst Kantorowicz ou pour les mécanismes de «l'opération symbolique »-qu'il enseignait d'une façon singulière et habitée à l'Université PanthéonSorbonne-, c'est bien parce qu'il avait entrepris de repérer au présent les nouveaux clercs d'État et le déploiement de leur imagination pour légitimer les politiques publiques. Présentées comme de simples « outils», les technologies du pouvoir, à commencer par la communication qui prend son essor politique en France dans les années 1980, relèvent en fait de l'idéologie, et permettent la diffusion d'un récit d'État. L'approche de Lucien Sfez et des Quaderni n'est pas pour autant technophobe (une position qu'il jugeait réactionnaire), elle entend montrer comment croyances, utopies et prophéties technophiles ont été développées, 
magnifiées et données comme capables de résoudre des problèmes politiques lancinants. Politisées comme s'il s'agissait des dernières ressources d'un appareil d'État aux abois, la communication et les technologies sont devenues les objets du culte d'une nouvelle religion d'État, essaimant en de multiples fictions d'État.

Le « jeu » politique - celui qui entend présenter des institutions performantes et rationnelles s'est ainsi éclaté en de multiples mythes plus ou moins abâtardis : dogmatique de la communication, jeu sur les symboles, mythe de la convivialité, de la politique culturelle avec son Ministère romantique, de l'évaluation au nom de l'efficacité, mythe conspirationniste qui dessine un pouvoir caché derrière l'État apparent, ou encore mythe de la télématique, devenue le numérique et sa toute-puissance réticulaire. Sans oublier le mythe de la bonne santé de la planète, transformé aujourd'hui en un discours écologique qui s'est d'autant plus facilement naturalisé qu'il portait sur la nature et qui charrie son lot d'inquiétudes et de scénarios dystopiques. Ni non plus le mythe de la réforme de l'État: New public management, Révision générale des politiques publiques, « choc de simplification » administrative, expertise scientiste vulgarisée, ou think tanks transmutés en auxiliaires de la décision. Ainsi, les Quaderni ont-ils exploré systématiquement les grandes croyances, formées ou en formation, qui président à l'action publique.

À leur manière, les dizaines de contributeurs de la revue, souvent venus d'horizons académiques différents, ont eu à cœur de répondre à nouveaux frais à la question originelle de Robert Dahl : «Qui gouverne? ». Les saints et les maires à
Naples, l'imaginaire technologique dans les pays du Nord, l'imaginaire biotechnologique quand la médecine vise la santé parfaite, la production des outils de la "bonne démocratie ", c'està-dire participative aujourd'hui, les politiques territoriales, les médias de masse et Internet de nos jours, et bien sûr d'innombrables acteurs politiques qui sont les réceptacles et les diffuseurs dociles des discours dominants. Car, en apparence plus anecdotiques, les « modes » techniques et langagières font sens pour ceux qui les adoptent et les défendent, qui ne considèrent ni leur évanescence ni leur superficialité. Le travail académique trouve dans leur déconstruction et leur critique sa nécessité absolue, et c'est dans ce mouvement que s'inscrit ce numéro 99-100.

Lucien Sfez s'inquiétait souvent que la conscience historique de ses contemporains soit lestée du poids des références anciennes et des récits objectivés totalisants, car ils empêchent toute imagination réellement réformiste et toute réflexivité sur les fonctionnements institutionnels. C'est en philosophe inquiet de cette tendance, qu'il avait nommée le « tautisme», et dans la quête séculaire du «bon gouvernement » qu'il a fondé Quaderni : une revue libre pour des esprits libres.

Nous sommes honorés de prendre la suite de Quaderni, que nous a confiée le comité de rédaction de la revue, pour en perpétuer l'esprit. 